\title{
A Fuzzy Genetic Based Classifier P System to Predict Cell Aging
}

\author{
Lamiaa Hassaan Ahmed, Amr Ahmed Badr, and Ibrahim Farag Abd El-Rahman
}

\begin{abstract}
P systems are computational models that simulate the structure and functions of a living cell. Fuzzy logic deals with approximate reasoning rather than fixed. A classifier system is a machine learning system that helps to create new rules that can be used in classification in order to add new information to a given database. Cell aging is one of the main phases of any cell cycle. The rate of aging progression may vary from a person to another; furthermore, the cells of the same organ do not age in the same rate. In this paper, we are creating a classifier system with the structure and functions of $P$ systems. The proposed classifier $P$ system deals with imprecise biological data of cell aging, so the new rules generated by the system should be evaluated using a fuzzy rule base. Transition rules and inhibitors accompany the $P$ system and executed in a parallel manner.
\end{abstract}

Index Terms-Classifier systems, fuzzy p systems, natural computing, $p$ systems, $p$ system with inhibitors.

\section{INTRODUCTION}

A P system is a computational model that is based on the idea of cellular membrane structure and functions. It was presented by Gh. Paun in [1]. It is a branch of natural computing whose initial goal is to abstract computing models from the structure and the functioning of living cells [2]. The chemical reactions controlling the change of molecules are represented by evolution rules -also called multiset rewriting rules [1,3]- and the chemical reactions controlling transportation of molecules without changing them are represented by communication rules $[1,3]$. Communication rules can either be symport/antiport rules or rules with carriers [4]. P systems employ these rules in order to transform from a computational status to another.

A simple transition P system is constructed of the form [3]:

where:

$$
I I=\left(O, C, \mu, w_{1}, w_{2}, \ldots, w_{n}, R_{l}, R_{2}, \ldots, R_{n}, i_{o}\right)
$$

- O: The alphabet of objects, i.e. cellular molecules.

- C: The alphabet of catalysts, if any.

- $\mu$ : The membrane structure. It consists of $\mathrm{n}$ membranes labeled with $1,2,3, . ., \mathrm{n}$.

- $w_{1}, w_{2}, \ldots, w_{n}$ : The strings over $O \cup C$, representing the multisets of objects initially present in all regions of the system membrane structure [3].

$-R_{1}, R_{2}, \ldots, R_{n}$ : The set of evolution rules associated with the regions of the system. An evolution rule can be a rule with an inhibitor. An object $\mathrm{x}$ is an inhibitor for a rule $u \rightarrow v$, denoted by $\left.u \rightarrow v\right|_{-x}$, if the rule is active only if inhibitor $\mathrm{x}$ is

Manuscript received September 22, 2011; revised October 31, 2011.

The authors are with Faculty of Computers and Information, Cairo University, Egypt (e-mail: lamia_work@yahoo.com; e-mail: a.badr.fci@gmail.com; e-mail: i.farag@fci-cu.edu.eg). not present in the region [5].

$-\mathrm{i}_{\mathrm{o}}$ : The output region. It will take one of the labels $1,2, \ldots \mathrm{n}$. Objects are assigned to rules by choosing rules and objects non-deterministically. Also, the chosen multiset of rules should be applicable to the chosen multiset of objects currently available. When no other rules can be applied on the current multiset of objects, the multiset of rules is said to be maximal. Different rules can be applied on different objects in parallel. We can conclude that $\mathrm{P}$ systems run in a maximally parallel non-determinitic manner [4].

\section{A. Fuzzy Logic}

Fuzzy Logic was initiated in 1965 [6]. It is a multivalued logic that allows intermediate values to be defined between conventional evaluations like true/false, yes/no, high/low, etc. Notions like rather tall or very fast can be formulated mathematically and processed by computers, in order to apply a more human-like way of thinking in the programming of computers [7]. Fuzzy logic is a useful theory to present inexact or imprecise terms like temperature (cold, worm or hot), height (very tall, tall, average, short, or very short). Each fuzzy term -linguistic term- is represented by a fuzzy set starting from the minimum value to the maximum value of each attribute. The membership function is a graphical representation of the magnitude of participation of each input. An example of the membership function of a linguistic variable is shown in fig. 1 [8]. Notice that trapezoidal functions or triangular functions or both can be used.
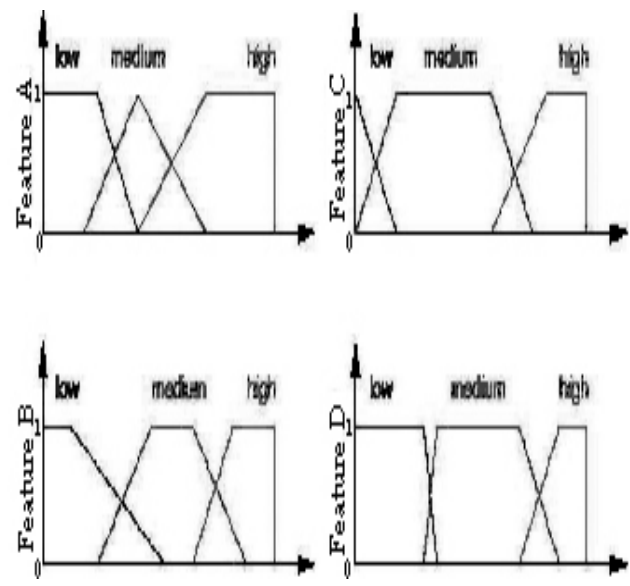

Fig. 1. Examples of membership functions of a linguistic variable

\section{B. Classifier Systems and genetic algorithms}

A Classifier System (CS) is a machine learning system that learns syntactically simple string rules, called classifiers, as introduced in [9]. A classifier system is a general machine learning system applicable to diverse environments, able to learn with incomplete information and classify the environment into hierarchies. It receives information about 
the environment, performs internal processing and then effects the environment. It then uses feedback about the effect on the environment to learn from the experience [10]. This arrangement has the classifier system in learning mode, because the classifier system is utilizing the feedback to learn from experience. Conversely, if no feedback is provided, the classifier system is in application mode. Application mode is utilized after sufficient learning is accomplished [10]. A genetic algorithm (GA) is a stochastic search algorithm based on the mechanics of natural selection and population genetics [10]. Genetic algorithms can be used as new information discovery mechanisms in classifier systems. The basic genetic algorithm operators involved in reproduction are Selection, crossover and mutation.

\section{Cell Aging:}

Aging is the accumulation of changes in a person over time [11]. It is an important part of all human societies reflecting the biological changes that occur. For every cell, there are different sites of producing substances that are responsible of cell aging. We will focus on the substances created by the reactions of the mitochondrial electron transport chain. The cell has its plasma membrane and the mitochondrion has an inner and an outer membrane. The composition and organization of these membranes are the keys to the bioenergetic activities of the mitochondrion [12].

In this paper, $\mathrm{P}$ systems with fuzzified transition rules with inhibitors are used for simulating the cellular functions and reactions that lead to cell aging. Section II of this paper shows a brief history of researches on cell aging using $\mathrm{P}$ systems, section III defines the concepts of cell aging and the reactions leading to it, section IV explains the structure and functions of the proposed system and finally section $\mathrm{V}$ which shows the results and conclusions of the system.

\section{LITERATURE SURVEY}

Parallelism of membrane system elements is identified and demonstrated using MIMD (Multiple Instruction Multiple Data) architecture in [13]. A simulator in MIMD architecture was used to implement a numerical P system to cellular aging. [13] was produced by researchers in Liverpool Hope Univ., Liverpool, UK. Also, a system based on fuzzy logic theory was created in [14] to predict cell aging. The conceptual network is casted into a fuzzy-logic, hybrid-intelligent framework based on interaction rules assembled from a priori knowledge [14]. It established an extendable and scalable computational approach capable to connect tractable molecular mechanisms with cellular network dynamics underlying the emerging aging phenotype. An application of genetic algorithms to $\mathrm{P}$ systems to compute squared numbers was done in [15].

\section{PROBLEM DEFINITION}

\section{A. The Mitochondrion and the Electron Transport Chain}

A living cell is surrounded by a plasma membrane (cell wall) which holds all the components of the cell like cytoplasm, the nucleus, the mitochondria, the ribosome, and different molecules like potassium, hydrogen, water, etc. The mitochondrion, as shown in fig. 2 [12], consists of two membranes, the outer membrane and the inner membrane. An intermembrane space is the area between the two membranes. The matrix is the compartment within the inner membrane [12].

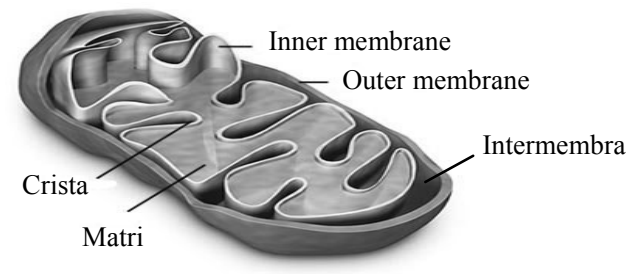

Fig. 2. The mitochondrial structure

The architecture of the mitochondrial inner membrane and its fluidity facilitate the interactions of molecules required to produce energy in the form of ATP molecules [12]. In order to produce energy for cellular activities, the mitochondrion carries out a big number of chemical reactions. One of the most well known chemical series done by the mitochondrion is the electron transport chain. It consists of a series of specific electron carriers which exist in the inner mitochondrial membrane [12]. The function of the electron transport chain is coupling a chemical reaction between an electron donor (such as $\mathrm{NADH}, \mathrm{FADH}_{2}$ ) and an electron acceptor (such as $\mathrm{O}_{2}$ ) to the transfer of $\mathrm{H}^{+}$ions across a membrane, through a set of mediating biochemical reactions. A simulation of the detailed processes and chemical reactions of cellular metabolism and energy production was done in [16]. There are four known chemical complexes that pass electrons from one to another. They are Complex I, Complex II, Complex III and Complex IV. NADH, FADH ${ }_{2}, \mathrm{QH}_{2}$ and $\mathrm{Cyt}_{\mathrm{c}}{ }^{2+}$ are the molecules carrying electrons within complexes I to IV respectively. When an electron passes through the entire electron transport chain, it unites with oxygen to produce water. The electron transport chain is shown in fig. 3 [12]. The equations and simulation of the electron transport chain in P systems are found in [16].

The final step of the mitochondrial oxidative metabolism is movement of protons back into the mitochondrial membrane and ATP formation. Protons now exist in the intermembrane space. They flow back across the inner mitochondrial membrane through the ATP synthesizing enzyme. This controlled movement of protons provides the energy required to phosphorylate ADP to ATP [12]. ATP synthase is sometimes described as Complex $\mathrm{V}$ of the electron transport chain. The equation of ATP formation at this stage will be [12]:

$$
A D P+P \rightarrow A T P+\mathrm{H}_{2} \mathrm{O}
$$

\section{B. Reactive Oxygen Species}

Reactive oxygen species (ROS) generally refers to molecules with an unpaired electron and also includes hydrogen peroxide $\mathrm{H}_{2} \mathrm{O}_{2}$ that does not have an unpaired electron [17]. They are highly reactive molecules. The mitochondrial electron transport system is the major site of ROS production as a normal product of cellular metabolism [18]. Uncontrolled increases in ROS levels can lead to chain reactions, which indiscriminately target protein, lipids, polysaccharides and DNA. Superoxide $\mathrm{O}_{2}{ }^{-}$is the precursor of most ROS within the cell. Superoxide can be turned into 
hydrogen peroxide $\mathrm{H}_{2} \mathrm{O}_{2}$ which can be fully reduced to water, or partially reduced to form hydroxyl radical $\mathrm{OH}^{-}$(one of the strongest oxidants in nature) [19].

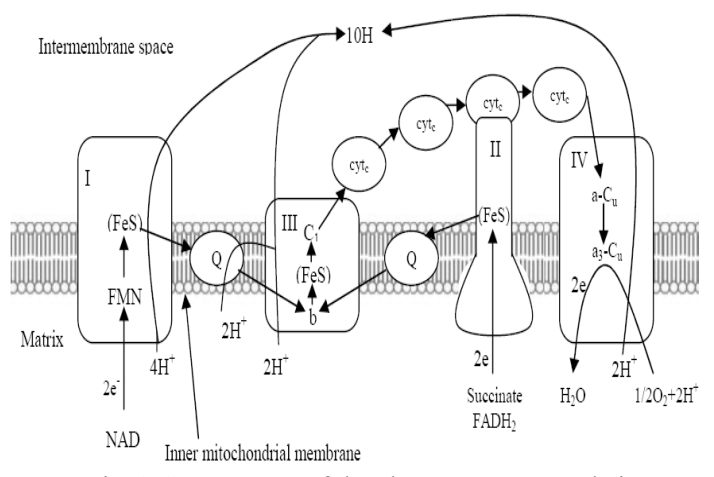

Fig. 3.Components of the electron transport chain

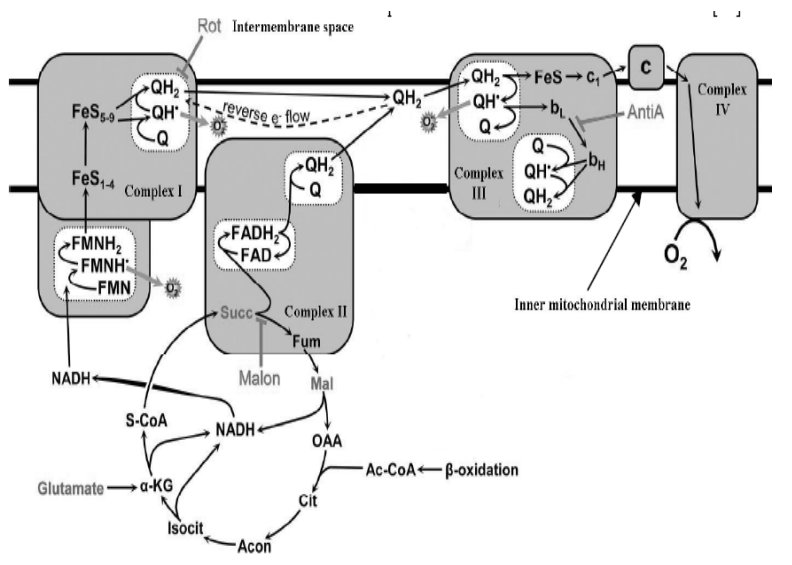

Fig. 4. Mitochondrial pathways of electron flow and $\mathrm{O} 2$ - production sites

ROS are produced when electrons are derived from metabolic reducing equivalents $\left(\mathrm{NADH}\right.$ and $\left.\mathrm{FADH}_{2}\right)$ and fed into the electron transport chain through either complex I or complex II, and eventually pass to $\mathrm{O}_{2}$ molecule to form $\mathrm{H}_{2} \mathrm{O}[20]$.

There are two main sites in the electron transport chain where ROS are produced: Complex I (NADH dehydrogenate) and Complex III (ubisemiquinone) [20,21]. Several studies have shown that both sites generate only $\mathrm{O}_{2}^{-}$ as opposed to a mixture of partially reduced oxygen species.

Hydrogen peroxide $\mathrm{H}_{2} \mathrm{O}_{2}$ is produced as a secondary product via $\mathrm{O}_{2}^{-}$dismutation [21]. ROS can be produced from complex I by either forward or reverse electron transfer [21].

In forward electron transfer, superoxide will be produced by complex I. This production can be augmented by the complex I specific inhibitor rotenone. Rotenone-Rot in fig. 4 [22]- blocks the quinone binding site causing electrons to back up and fully reduce upstream redox centres [21]. ROS can also be produced by complex I from reverse electron transfer from complex II. Succinate reduces quinone through complex II. If membrane potential is high, this drives the electrons "back" to complex I generating a significant amount of ROS [21].

This reaction can be blocked by rotenone since it inhibits this electron transfer. It can also be inhibited by reducing membrane potential. If membrane potential is low it is thermodynamically more favorable to transfer the electrons to complex III [21]. See fig. 4 [22]. Another site of ROS production is complex III. Complex III only produces superoxide at high rates when inhibited by antimycin A [21]. Antimycin is AntiA in fig.4.

\section{Cell Aging the Mitochondrial ROS}

One hypothesis is that ROS production in mitochondria determines the rate of the aging process [23]. The accumulation of any ROS radicals may cause cell damage including lipids, membranes, proteins, nucleic acids and cell death [23]. Studies showed that longer-lived species produce less ROS from isolated mitochondria [24].

\section{Factors of ROS Production}

Hundreds of medical studies have discussed the factors of ROS production. In [22], a derived rate of ROS generation database was provided. The factors that affect $\mathrm{O}_{2}{ }^{-}$generation were complex I-FMN, complex II backflow, complex III-Qu and $\beta$-oxidation ETF:QOR. Also, in [22], the mitochondrial membrane potential was a factor with a great effect on $\mathrm{O}_{2}{ }^{-}$ generation rate. Table I is constructed from data presented in [22]. Notice that the values of items in table I were transformed in order to unify the measuring unit of $\mathrm{O}_{2}{ }^{-}$.

TABLE I: RATES OF ROS (O2-) GENERATION

\begin{tabular}{|c|c|c|c|}
\hline $\begin{array}{c}\text { Comple } \\
\text { FMN }\end{array}$ & $\begin{array}{c}\text { Comple } \\
\text { X I } \\
\text { Back- } \\
\text { flow }\end{array}$ & $\begin{array}{c}\text { Complex } \\
\text { III } \\
Q\end{array}$ & $\begin{array}{c}\mathrm{O}_{2}^{-} \\
\mathrm{n} \mu\end{array}$ \\
\hline 0 & 0 & 0 & 0 \\
\hline 6.67 & 2.19 & 1.69 & 10 \\
\hline 9.45 & 3.55 & 2.66 & 20 \\
\hline 13.0 & 5.97 & 4.33 & 50 \\
\hline 15.04 & 7.99 & 5.88 & 100 \\
\hline 16.3 & 9.84 & 7.62 & 200 \\
\hline 16.87 & 11.63 & 10.0 & 500 \\
\hline 16.71 & 12.45 & 11.66 & 1000 \\
\hline 16.33 & 12.93 & 13.02 & 2000 \\
\hline 15.86 & 13.25 & 14.25 & 5000 \\
\hline 15.63 & 13.36 & 14.78 & 10000 \\
\hline 15.4 & 13.42 & 15.07 & 20000 \\
\hline
\end{tabular}

\section{THE Proposed SYSTEM}

\section{A. An Overview}

We are proposing a system that consists of $\mathrm{N}$ number of $\mathrm{P}$ systems with initial values. The $\mathrm{P}$ systems will produce rule sets which are to be fuzzified, to be used to classify the training patterns in table I to get their fitness and to go through crossover and mutation. Selection, crossover and mutation of the fuzzified rule set will be repeated for a predefined number of generations. The final output will be the rule set with the best fitness value.

\section{B. The Construct of the P Systems}

This paper is proposing a system that simulates the reactions leading to cell aging. The simulator is based on the concept of membrane systems -P systems- with evolution fuzzy rules and inhibitors. This paper is an extension to [16] that is, a $\mathrm{P}$ simulator of the cell cycle including metabolic processes and cell aging can be assembled from [16] and this proposed system. Fig. 5 shows the construct of each P system within the classifier system. The $\mathrm{P}$ system form of the 
proposed simulator will be:

where:

$$
I I_{\text {age }}=\left(O, C, \mu, w_{3}, w_{4}, w_{5}, R_{e 3}, R_{e 4}, R_{e 5}, i_{o}\right)
$$

- O: The alphabet of objects.

$\mathrm{O}=\left\{\mathrm{O}_{2}^{-}, \mathrm{FMN}, \mathrm{FMNH}, \mathrm{FMNH}_{2}, \mathrm{UQH}_{2}, \mathrm{UQ}, \mathrm{QH} ;\right.$ Rot, Anti_A

$-\mu$ : The membrane structure [4]. The plasma membrane cell wall- will take label 1 , the outer mitochondrial membrane will take label 2 , the inner mitochondrial membrane will take label 3 and the complexes I and III of the electron transport chain will be inside the inner mitochondrial membrane taking labels 4 and 5 respectively.

The structure is $\left.\mu={ }_{1}\left[2\left[3[4]_{4}[5]_{5}\right]_{3}\right]_{2}\right]_{1}$.

- $\quad w_{3}, w_{4}, w_{5}$ : The strings over $\mathrm{O} \cup \mathrm{C}$ [4], representing the multisets of objects and carriers initially present region 3, 4 and 5 respectively.

$$
\begin{aligned}
\mathrm{w}_{3}= & \left\{\mathrm{QH}_{2}, \mathrm{O}_{2}^{-}\right\} \\
\mathrm{w}_{4}= & \left\{\# \mathrm{FMN}, \mathrm{FMNH}^{-}, \mathrm{FMNH}_{2}, \quad \# \mathrm{UQ}, \quad \# \mathrm{UQH} ;\right. \\
& \left.\# \mathrm{UQH}_{2}, \mathrm{Rot}, \mathrm{O}_{2}^{-}\right\} \\
\mathrm{w}_{5}= & \left\{\# \mathrm{UQ}, \# \mathrm{UQH} ; \# \mathrm{UQH}_{2}, \mathrm{O}_{2}^{-}, \text {Anti_A }\right\}
\end{aligned}
$$

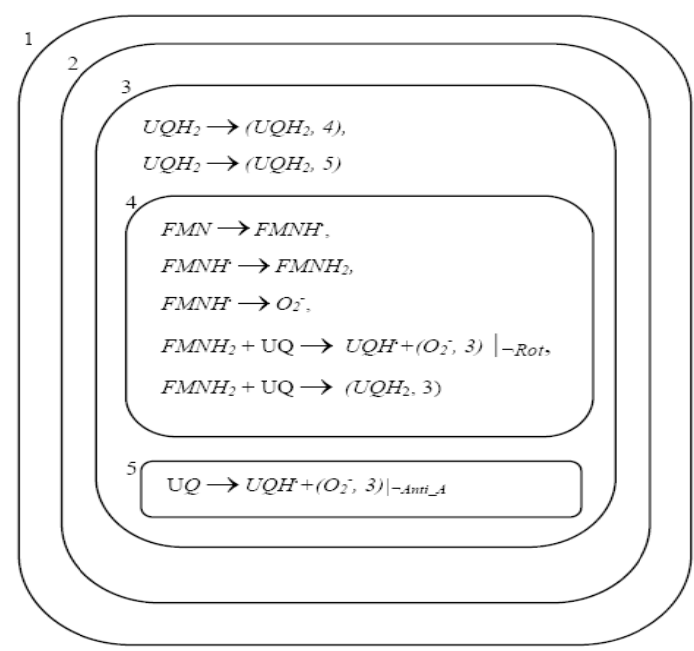

Fig. 5. The construct of the P systems

$-\mathrm{R}_{\mathrm{e} 3}, \mathrm{R}_{\mathrm{e} 4}, \mathrm{R}_{\mathrm{e} 5}$ : The set of evolution rules associated with the three regions of the system. They are in the form $u \rightarrow v$ where $u$ is a string over $\mathrm{O}$ and $v$ is a string over $\mathrm{O}_{\text {tar }}$, where $\mathrm{O}_{\text {tar }}=\mathrm{O} \times \mathrm{TAR}$ [4] for $\mathrm{TAR}=\{1,2,3,4,5\}$. This means that every reaction indicates the output objects and the region to which the output objects will be moved. When there is no target indicator i.e. 1 or 2 or 3 , this means that the outcome of the applied reaction will remain in the current region. Also, an evolution rule can be in the form $\left.u \rightarrow v\right|_{\neg x}$, where the rule is active only if inhibitor $\mathrm{x}$ is not present in the region [5].

$$
\begin{aligned}
& \mathrm{R}_{\mathrm{e} 3}=\{ \\
& \mathrm{r}_{1}=U Q H_{2} \rightarrow\left(U Q H_{2}, 4\right), \\
& r_{2}=U Q H_{2} \rightarrow\left(U Q H_{2}, 5\right) \\
&\} \\
& \mathrm{R}_{\mathrm{e} 4}=\{ \\
& \mathrm{r}_{3}=F M N \rightarrow F M N H^{\circ}, \\
& \mathrm{r}_{4}=F M N H \rightarrow \mathrm{FMNH}_{2}, \\
& \mathrm{r}_{5}=F M N H \rightarrow \mathrm{O}_{2}^{-},
\end{aligned}
$$

$$
\begin{gathered}
\mathrm{r}_{6}=\mathrm{FMNH}_{2}+\mathrm{UQ} \rightarrow U Q H^{+}+\left.\left(\mathrm{O}_{2}^{-}, 3\right)\right|_{\neg \text { Rot }}, \\
\mathrm{r}_{7}=\mathrm{FMNH}_{2}+\mathrm{UQ} \rightarrow\left(\mathrm{UQH}_{2}, 3\right) \\
\quad\} \\
\mathrm{R}_{\mathrm{e} 5}=\{ \\
\mathrm{r}_{8}=\mathrm{UQ} \rightarrow U Q H^{+}+\left.\left(\mathrm{O}_{2}^{-}, 3\right)\right|_{\neg A n t i} A \\
\quad\}
\end{gathered}
$$

- $\mathrm{i}_{\mathrm{o}}$ : The output region. $\mathrm{i}_{3}$ is the output membrane of the system. $\mathrm{O}_{2}^{-}$molecules are sent to the inner mitochondrial membrane and counted to measure cell aging.

\section{Fuzzy rules Base and Fuzzy Reasoning Based} Cla

The current system is proposing the fuzzification of the rules that are critical in ROS generation. Table I shows that different amounts of $\mathrm{O}_{2}^{-}$produced given different amounts of FMN, electron backflow to complex I and Q of complex III. The following steps are done in order to apply fuzzy reasoning:

1) The P system shown in the previous subsection can be used to generate rule set with new attribute values. Rules within rule sets will be in the form:

$R_{j}$ : if $x 1$ is $A_{j 1}$ and $x_{2}$ is $A_{j 2}$ and ..... and $x_{n}$ is $A_{j n}$ then class $C_{j}$

where:

$R_{j}:$ is the label of the $\mathrm{j}$-th linguistic rule.

$\mathrm{x}=\left(\mathrm{x}_{1}, \mathrm{x}_{2}, \ldots, \mathrm{x}_{n}\right)$ : is an $\mathrm{n}$-dimensional pattern vector representing the continuous attributes (weight, height, age, etc..).

$\mathrm{A}_{j i}$ : is a linguistic terms given for the $\mathrm{i}$-th attribute.

$\mathrm{C}_{j}$ : is the consequent class of the rule.

2) For every rule set, fuzzify every attribute including the class attribute using a pre specified number of fuzzy sets (small, medium, and large) or (very small, small, medium, large and very large), etc. Using the following equation, calculate the membership function for every attribute:

$$
f(x ; a, b, c, d)=\left\{\begin{array}{cc}
0, & x \leq a \\
\frac{x-a}{b-a}, & a \leq x \leq b \\
\frac{d-x}{d-c}, & b \leq x \leq c \\
0, & d \leq x
\end{array}\right\}
$$

If $X=\{1,2,3,4,5,6,7,8,9,10\}$ then, $f(x, 1,5,7,8)$ will be plot as in fig. 6 :

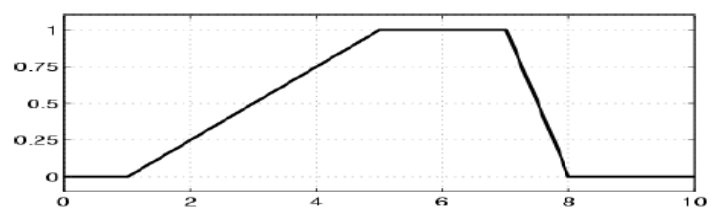

Fig. 6. An example of plotting a trapezoidal function

3) For every rule set, for every rule, calculate the compatibility grade [25]

$$
\mu A_{j}\left(x_{p}\right)=\mu A_{j 1}\left(x_{p 1}\right) \times \mu A_{j 2}\left(x_{p 2}\right) \times \ldots \times \mu A_{j n}\left(x_{p n}\right)
$$

where: 
$A_{j}=\left(A_{j 1}, A_{j 2}, \ldots, A_{j n}\right)$, it is used to denote the antecedent part "if $\mathrm{x}_{1}$ is $\mathrm{A}_{\mathrm{j} 1}$ and ....and $\mathrm{x}_{\mathrm{n}}$ is $\mathrm{A}_{\mathrm{ji}}$ " of the linguistic rule.

$x_{p}=\left(x_{p 1}, x_{p 2}, \ldots, x_{p n}\right):$ is an $\mathrm{n}$-dimensional pattern vector representing the continuous attributes.

4) For every rule set, for every rule, calculate the total compatibility grade with the antecedent part [25]:

For each rule, calculate the total compatibility grade with the antecedent part of the rule using:

$$
\left|D\left(A_{j}\right)\right|=\sum_{p=1}^{m} \mu A_{j}\left(x_{p}\right)
$$

where:

$\mathrm{D}$ : the set of the given training patterns $\mathrm{D}=\left(x_{1}, x_{2}, \ldots, x_{m}\right)$, the cardinality of $\mathrm{D}$ is $\mathrm{m}$ (i.e., $|\mathrm{D}|=\mathrm{m}$ ),

$\mathrm{D}\left(A_{j}\right)$ : the fuzzy set of compatible training patterns with the antecedent part $A_{j}$ of the linguistic rule $R_{j}$,

$\left|\mathrm{D}\left(A_{j}\right)\right|$ : the cardinality of the fuzzy set $\mathrm{D}\left(A_{j}\right)$. In the case of interval discretization - where $A_{j i}$ is an interval, $\left|\mathrm{D}\left(A_{j}\right)\right|$ is the number of compatible training patterns with the antecedent part $A_{j}$.

5) For every rule set, for every rule, calculate the total compatibility grade with both the antecedent part and the consequent part [25]:

$$
\left|D\left(A_{j}\right) \cap D\left(C_{j}\right)\right|=\sum_{p \in C_{j}} \mu A_{j}\left(x_{p}\right)
$$

where:

$D\left(A_{j}\right) \cap D\left(C_{j}\right)$ is the fuzzy set of compatible training patterns with both antecedent part $\mathrm{A}_{\mathrm{q}}$ and the consequent class $\mathrm{C}_{\mathrm{j}}$.

6) For every rule set, for every rule, calculate the rule weight [25]

$$
c\left(A_{j} \Rightarrow C_{j}\right)=\frac{\left|D\left(A_{j}\right) \cap D\left(C_{j}\right)\right|}{\left|D\left(A_{j}\right)\right|}=\frac{\sum_{p \in c_{i}} \mu A_{j}\left(x_{p}\right)}{\sum_{p=1}^{m} \mu A_{j}\left(x_{p}\right)}
$$

- $c\left(A_{j} \Rightarrow C_{j}\right)$ is called confidence. It is used to describe the definition of the rule weight of each linguistic rule. It is the ratio of compatible patterns with both the antecedent part $\mathrm{A}_{\mathrm{j}}$ and the consequent class $\mathrm{C}_{\mathrm{j}}$ to compatible patterns with the antecedent part $\mathrm{A}_{\mathrm{j}}$. The confidence can be directly used as the rule weight $C_{j}$ of the linguistic rule $R_{j}$. That is, the rule weight $\mathrm{CF}_{\mathrm{j}}$ of the linguistic rule $\mathrm{R}_{\mathrm{j}}$ is specified as:

$$
C F_{j}=c\left(A_{j} \Rightarrow C_{j}\right)
$$

7) For every rule set, for every rule, classify the training patterns saved in the training file; this will be done using the single winner-based method where a single rule is responsible for the classification of each training pattern.

The single winner rule $R_{w}$ in the rule set $S$ is determined for a new pattern $\mathrm{x}_{\mathrm{p}}=\left(\mathrm{x}_{\mathrm{p} 1}, \mathrm{x}_{\mathrm{p} 2}, \ldots \ldots \mathrm{x}_{\mathrm{pn}}\right)$ as [25]:

$$
\mu A_{w}\left(x_{p}\right) \cdot C F_{j}=\max \left\{\mu A_{j}\left(x_{p}\right) \cdot C F_{j} \mid R_{j} \in S\right\}
$$

That is, the winner rule has the maximum product of the compatibility grade and the rule weight. If multiple linguistic rules have the same maximum product but different consequent classes for the new pattern $x_{p}$ then the classification of $x_{p}$ is rejected. The classification is also rejected when there are no linguistic rules compatible with the new pattern $\mathrm{x}_{\mathrm{p}}[25]$

\section{Genetic Operations}

In order to widen the range of producing correct rules, genetic algorithms can be applied. Genetic algorithms can also work with different representations allowing even wider applicability. Genetic operations done on rule sets can be summarized in the following steps:

\section{1) Fitness calculation}

The evaluation of each fuzzy rule is performed by classifying all the given training patterns by the rule set $S$ using the single winner-based method. After all the given training patterns are classified by $S$, the fitness value of each rule set fitness $\left(\mathrm{S}_{\mathrm{i}}\right)$ of each fuzzy rule $\mathrm{R}_{\mathrm{j}}$ in $\mathrm{S}$ is calculated as the total number of correctly classified training patterns by $S_{i}$ [25]. fitness $\left(\mathrm{S}_{\mathrm{i}}\right)=\Sigma_{\mathrm{RjESi}}$ fitness $\left(\mathrm{R}_{\mathrm{j}}\right), \mathrm{i}=1,2, \ldots, \mathrm{N}$

2) Selection:

For every rule set $S_{i}$, select predefined number $\mathrm{N}_{\text {select }}$ random rules for crossover.

$R_{\text {cross }}=\left\{R_{\text {cross }-1}, R_{\text {cross }-2}, R_{\text {cross }-3}, \ldots, R_{\text {cross }-N}\right\}$

where: $R_{\text {cross }-i}$ is a subset of the $i^{\text {th }} \mathrm{P}$ system rule set.

3) Crossover:

Given two $\mathrm{P}$ systems $\mathrm{II}_{1}$ and $\mathrm{II}_{2}$ with rule sets $R_{1}$ and $R_{2}$ respectively, where $\mathrm{R}_{1}$ consists of the two partitions $R_{\text {cross- }}$ $R_{1-1}$ and $R_{2}$ consists of the two partitions $R_{2-1} R_{\text {cross }-2}$. The off springs $\mathrm{II}_{1}{ }^{*}$ and $\mathrm{II}_{2}{ }^{*}$ produced by crossover will be $\mathrm{II}_{1}{ }^{*}$ with $\mathrm{R}_{1}{ }^{*}=\left\{\mathrm{R}_{2-1} \mathrm{R}_{\text {cross- } 1}\right\}$ and $\mathrm{II}_{2}{ }^{*}$ with $\mathrm{R}_{2}{ }^{*}=\left\{\mathrm{R}_{\text {cross-1 }} \mathrm{R}_{2-1}\right\}$.

An example: Consider two $\mathrm{P}$ systems $\mathrm{II}_{1}$ and $\mathrm{II}_{2}$ with rule sets $\mathrm{R}_{1}=\left\{\mathrm{r}_{1-1}, \mathrm{r}_{1-2}\right\}$ and $\mathrm{R}_{2}=\left\{\mathrm{r}_{2-1}, \mathrm{r}_{2-2}, \mathrm{r}_{2-3}\right\}$ with $\mathrm{R}_{\text {cross- } 1}=\left\{\mathrm{r}_{1-}\right.$ $2\}$ and $\mathrm{R}_{\text {cross- }}=\left\{\mathrm{r}_{2-1}, \mathrm{r}_{2-2}\right\}$ respectively. The new obtained offsprings will be $\mathrm{II}_{1}{ }^{*}$ with $\mathrm{R}_{1}{ }^{*}=\left\{\mathrm{r}_{1-1}, \mathrm{r}_{2-1}, \mathrm{r}_{2-2}\right\}$ and $\mathrm{II}_{2}{ }^{*}$ with $\mathrm{R}_{2}^{*}=\left\{\mathrm{r}_{1-2}, \mathrm{r}_{2-3}\right\}$

4) Mutation:

After crossover is applied, any symbol of symbol "value" of the generated strings is randomly replaced with a different symbol from the given alphabet by a mutation operation.

An example: Given the rule $a \rightarrow b c$, a new rule can be produced like $\mathrm{y} \rightarrow \mathrm{bc}$ or $\mathrm{a} \rightarrow$ bd by mutation operation given that $\mathrm{y}$ and $\mathrm{d}$ are existing in the alphabet of the $\mathrm{P}$ system.

\section{5) Generation update}

The operations selection, crossover and mutation are iterated for a pre-specified number of generations. The newly produced rule sets will be used to replace the rule sets with the least fitness values to create a new generation. Fig. 7 shows a simple diagram of the proposed simulator. There are five main classes Membrane1, Membrane2, Membrane3, Membrane4 and Membrane5 which represent the plasma membrane, the mitochondrial outer membrane, the mitochondrial inner membrane complex I and complex III respectively.

\section{EXPERIMENTS AND RESULTS}

The output of the system is the best rule set with the highest fitness value after applying genetic operations for a pre specified number of generations. The fitness values produced by all generations are given as an input to a plotting function in order to produce a graph showing the phases of 
system performance. Many experiments were performed on the cell aging, wine and liver disorders datasets. The latter two datasets can be found in [26]. The functions of each membrane will be executed simultaneously using Java threads to preserve the condition of parallelism in applying rules.

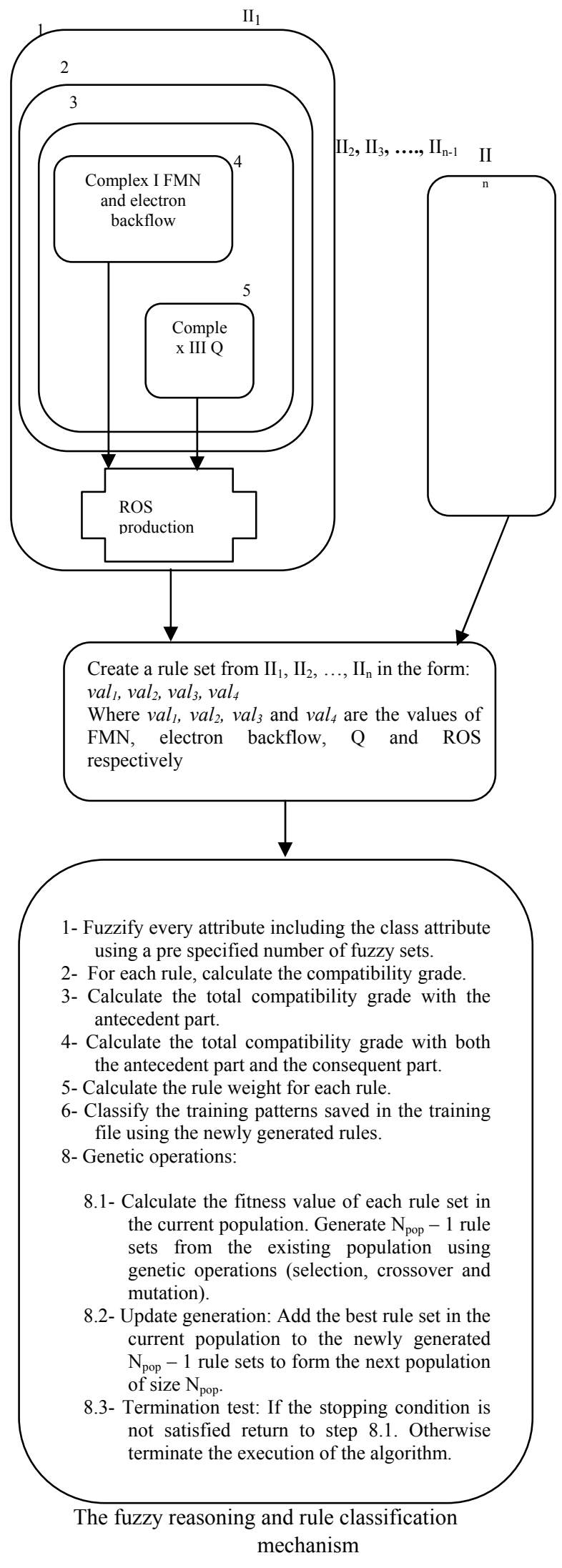

Fig. 7. A simple diagram of the proposed system

\section{A. An Example}

The input values to the system are the number of $\mathrm{P}$ systems, number of linguistic terms used to fuzzify the attributes, FMN molecules, Q molecules, Rotonine molecules and Anti_A molecules.

\begin{tabular}{l} 
TABLE II: FITNESS VALUES \\
OF THE FIRST GENERATION \\
\begin{tabular}{|c|c|}
\hline P System & Fitness \\
\hline $\mathrm{II}_{3}$ & 0 \\
\hline $\mathrm{II}_{18}$ & 0 \\
\hline $\mathrm{II}_{4}$ & 0 \\
\hline $\mathrm{II}_{8}$ & 0 \\
\hline $\mathrm{II}_{14}$ & 0 \\
\hline $\mathrm{II}_{12}$ & 0 \\
\hline $\mathrm{II}_{15}$ & 0 \\
\hline $\mathrm{II}_{16}$ & 0 \\
\hline $\mathrm{II}_{17}$ & 0 \\
\hline $\mathrm{II}_{5}$ & 0 \\
\hline $\mathrm{II}_{2}$ & 0 \\
\hline $\mathrm{II}_{20}$ & 1 \\
\hline $\mathrm{II}_{1}$ & 1 \\
\hline $\mathrm{II}_{9}$ & 1 \\
\hline $\mathrm{II}_{19}$ & 1 \\
\hline $\mathrm{II}_{7}$ & 2 \\
\hline $\mathrm{II}_{13}$ & 3 \\
\hline $\mathrm{II}_{6}$ & 3 \\
\hline $\mathrm{II}_{11}$ & 3 \\
\hline $\mathrm{II}_{10}$ & 4 \\
\hline $\begin{array}{c}\text { Total } \\
\text { number of } \\
\text { classified } \\
\text { patterns }\end{array}$ & 19 \\
\hline & \\
\hline & \\
\hline & \\
\hline & \\
\hline & \\
\hline & \\
\hline
\end{tabular} \\
\hline
\end{tabular}

TABLE III: FITNESS VALUES OF

\begin{tabular}{|c|c|}
\hline \multicolumn{2}{|c|}{ GENERATION 1000} \\
\hline P System & Fitness \\
\hline $\mathrm{II}_{6}$ & 0 \\
\hline $\mathrm{II}_{12}$ & 0 \\
\hline $\mathrm{II}_{1}$ & 0 \\
\hline $\mathrm{II}_{4}$ & 0 \\
\hline $\mathrm{II}_{16}$ & 0 \\
\hline $\mathrm{II}_{17}$ & 0 \\
\hline $\mathrm{II}_{18}$ & 0 \\
\hline $\mathrm{II}_{15}$ & 0 \\
\hline $\mathrm{II}_{3}$ & 0 \\
\hline $\mathrm{II}_{5}$ & 1 \\
\hline $\mathrm{II}_{9}$ & 1 \\
\hline $\mathrm{II}_{2}$ & 1 \\
\hline $\mathrm{II}_{8}$ & 1 \\
\hline $\mathrm{II}_{10}$ & 1 \\
\hline $\mathrm{II}_{11}$ & 1 \\
\hline $\mathrm{II}_{13}$ & 2 \\
\hline $\mathrm{II}_{19}$ & 3 \\
\hline $\mathrm{II}_{20}$ & 4 \\
\hline $\mathrm{II}_{7}$ & 4 \\
\hline $\mathrm{II}_{14}$ & 4 \\
\hline $\begin{array}{c}\text { Total number } \\
\text { of classified } \\
\text { patterns }\end{array}$ & 23 \\
\hline
\end{tabular}

\section{B. Experimental Observations}

An experiment with $20 \mathrm{P}$ systems and 3 linguistic terms e.g. (small, medium and large) was done by the proposed system. Table II shows the fitness values of the first generation of the genetic operations. Table III shows the fitness values of the $1000^{\text {th }}$ generation.

When we compare the total number of classified patterns in table II and table III, we will find that the difference is only more four classified patterns. The reason is that the rule set with the highest fitness is always delivered from a generation to the next. This will always keep the best rule set from the first generation to the last one.

Fig. 8 shows a comparison of the outputs of three experiments. The first experiment is done using $10 \mathrm{P}$ systems, the second experiment is done using $20 \mathrm{P}$ systems and the third experiment is done using $30 \mathrm{P}$ systems. All the experiments have the same number of fuzzy linguistic terms which is 3 .

We can see that the performance values along any of the three experiments lies within a small range. The reason is that, as mentioned before, the best rule set is always handed from a generation to another. The experiment with the $10 \mathrm{P}$ systems had the lowest performance, while the experiment with the 30 P systems gave the highest performance

Three other experiments with 10, 20 and $30 \mathrm{P}$ systems were done using 5 linguistic terms for fuzzy partitioning. Fig. 9 shows the results of the three experiments. We notice that the performances of the three systems are lower than the performances of the same experiments using 3 linguistic terms for fuzzy partitioning in fig. 8 . The experiment with the 
less number of linguistic terms for fuzzy partitioning performed better. Furthermore, we may compare the performance of the proposed system with the performance of the Pittsburg approach for classification as they both genetic operations on rule sets to achieve the same goal. Fig. 10 is a comparison between the performances of the proposed $\mathrm{P}$ system and the Pittsburg approach tested on the wine dataset. Also, the same comparison is done using 5 linguistic terms for fuzzy partitioning; it is shown in fig. 11. It is also done on the liver disorders dataset. Fig. 10 and fig. 11 show that using a $\mathrm{P}$ system to produce rules achieved higher performances. The reason is that the $\mathrm{P}$ system produces rules depending on the training file, while the Pittsburg approach produces random

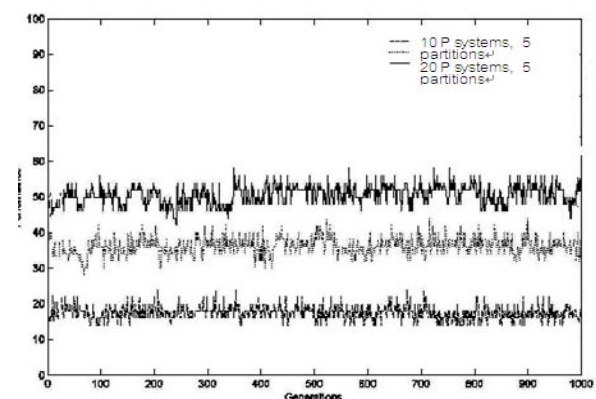

Fig. 9. Performances of three experiments using 10, 20 and $30 \mathrm{P}$ systems with five linguistic terms for fuzzy partitioning.

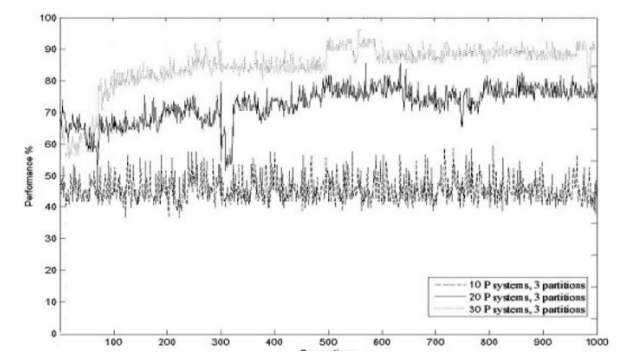

Fig. 8. Performance of 10,20 and 30 classifier P systems with three linguistic terms for fuzzy partitioning.

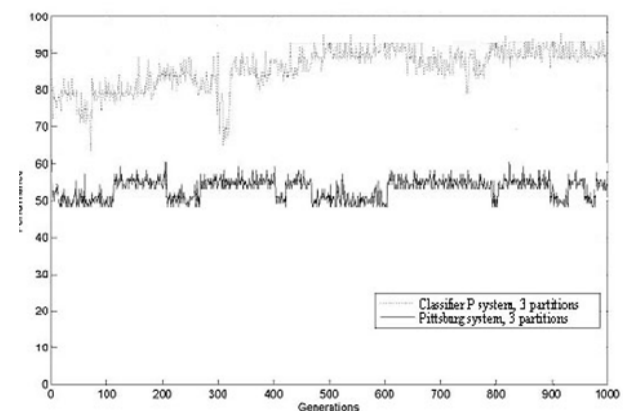

Fig. 10. Performances of the proposed classifier P system and the Pittsburg approach using 3 linguistic terms for fuzzy partitioning.

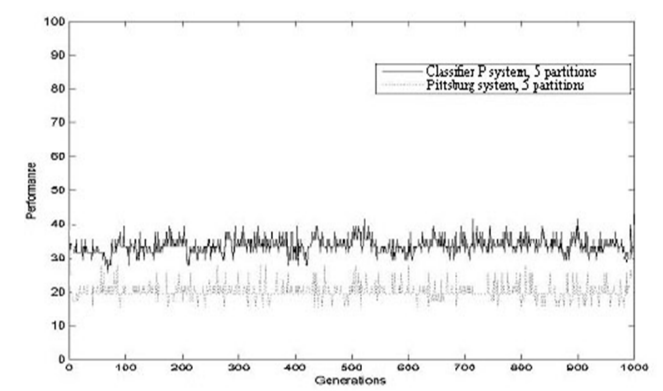

Fig. 11. Performances of the proposed P system and the Pittsburg approach using 5 linguistic terms for fuzzy partitioning.

\section{CONCLUSION AND FUTURE WORK}

$\mathrm{P}$ systems can be used to represent the biological activities of cells. This paper is intended as a representation of a classifier P simulator of cell aging in the framework of fuzzy logic and evolutionary algorithms. We first gave a brief on $\mathrm{P}$ systems, P systems with inhibitors, fuzzy logic, classifier systems based on genetic algorithms and cell aging. Second, we introduced the current state of the research concerning cell aging $\mathrm{P}$ systems and cell aging fuzzy systems. Third, the bioliogical background required for the proposed system and important reactions responsible of cell aging were explained. Fourth, the construction of the proposed simulator is presented. Finally, the simulator is tested and the results are discussed. Classifier P systems proved their power. We think our work above contributes to the field of membrane computing. We suggest calculating the fitness of rules of each $\mathrm{P}$ system and selecting the rules with the highest fitness values to use for crossover among the rules sets of the $P$ systems, then calculate the fitness of each rule set and add the rule set with the highest fitness to the current population. This future work is to be done as a trial to improve the performance of the proposed system.

\section{REFERENCES}

[1] P. Gh, Computing with membranes. Journal of Computer and System Sciences, 2000, 61(1):108-143.

[2] P. Gh. (2005). Membrane computing: Main ideas, basic results, applications. Retrieved on July $29^{\text {th }} 2008$ from www.dp.univer.it

[3] P. Gh.(2004). The $12^{\text {th }}$ Estonian Winter School in Computer Science (EWSCS). Introduction to membrane computing. Retrieved on July $1^{\text {st }}$ 2010 from http://cs.ioc.ee/yik/schools/win2007/paun/

[4] P. Gh, Membrane computing. An introduction. Springer, 2002.

[5] M. Ionescu and D. Sburlan, On P Systems with Promoters/Inhibitors. Journal of Universal Computer Science, 2004, vol. 10, no. 5, 581-599.

[6] L. A. Zadeh, Fuzzy Sets, Information and Control, 1965; 8: 338-353.

[7] L. A. Zadeh, "Making computers think like people" IEEE. Spectrum, 8/1984, pp. 26-32.

[8] M. Hellmann, Fuzzy Logic Introduction, Universit'e de Rennes, France. Retrieved from citeseerx.ist.psu.edu/viewdoc/download?doi=10.1.1.85...pdf on September 07, 2011.

[9] J. H. Holland and J. S. Reitman, Cognitive Systems Based on Adaptive Algorithms, in D.A. Waterman and F. Hayes-Roth (eds.), Pattern-Directed Inference Systems, Academic Press, NY, 1978.

[10] A. Robert Richards, Zeroth-Order Shape Optimization Utilizing a Learning Classifier System. $\mathrm{PhD}$ thesis, Stanford University, California, USA, 1995

[11] B. R. L and A. C. S, Living and dying for sex. A theory of aging based on the modulation of cell cycle signaling by reproductive hormones. Gerontology 2004， 50 (5): 265-90. doi:10.1159/000079125. PMID 15331856.

[12] K. Gerald, Cell and molecular biology: Concepts and eExperiments. (Fifth edition). John Wiley and Sons Inc, 2004.

[13] D. Reid, A. Oddie, and P. Hazlewood, Dept. of Computer Science, Liverpool Hope Univ., Liverpool, UK, Parallel Numerical P systems using MIMD based architecture, Bio-Inspired Computing: Theories and Applications (BIC-TA), IEEE International Conference 2010.

[14] A. Kriete, W. J. Bosl, and G. Booker, Rule-Based Cell Systems Model of Aging using FeedbackLoop Motifs Mediated by Stress Responses, PLoS Comput Biol 2010, 6(6): e1000820. doi:10.1371/journal.pcbi.1000820 JOURNAL[1].pcbi.1000820.pdf

[15] G. Escuela and A. Miguel Gutierrez-Naranjo, Eighth Brainstorming Week on Membrane Computing, Fénix Editora, Sevilla, Spain ,2010.

[16] L. H. Ahmed, A. A. Badr, and I. F. Abd El-Rahman, A P-Simulator with Carriers of Cellular Respiration and Mitochondrial Oxidative Metabolism. International Journal of Computer Theory and Engineering, 2011, Vol. 3, No. 3, 448-456.

[17] D. Edgar, "Molecular Mechanisms of Aging in MTDNA Mutator Mice", Karolinska Institutet, Karolinska Institutet, Stockholm, Sweden, 2011. 
[18] D. T. P. A, J. C. Tilak, K. K. Boloor, S. S. Ketaki, S. G. Saroj, and R. D Lele, Free Radicals and Antioxidants in Human Health: Current Status and Future Prospects,. Journal of Association of Physicians of India 2004, (JAPI) 52: 796

[19] J. F. Turrens, Mitochondrial formation of reactive oxygen species, J Physiol 2003, 552(Pt 2): 335-344

[20] Y. Liu, G. Fiskum and D. Schubert, Generation of reactive oxygen species by the mitochondrial electron transport chain, Journal of Neurochemistry, 2002, 80, 780.787.

[21] F. Julio Turrens, Superoxide Production by the Mitochondrial Respiratory Chain. Bioscience Reports, Vol. 17, No. 1, 1997.

[22] L. David Hoffman and P. S. Brookes, Oxygen Sensitivity of Mitochondrial Reactive Oxygen Species Generation Depends on
Metabolic Conditions, The Journal of Biological Chemistry VOL. 284, NO. 24, pp. 16236-16245, June 12, 2009

[23] F. B. Oliveira, José Augusto Nogueira-Machado, and Míriam M. Chaves, The Role of Oxidative Stress in the Aging Process, The Scientific World Journal 2010, 10, 1121-1128

[24] H. H. Ku, U. T. Brunk, Relationship between mitochondrial superoxide and hydrogen peroxide production and longevity of mammalian species, Free Radic Biol Med 1993, 15(6): 621-627.

[25] H. Ishibuchi, T. Nakashima, and N. M. Classification and Modeling with Linguistic Information Granules. Springer, 2005.

[26] University of California, Irvine. "The Machine Learning Repository". Retrieved form: http://archive.ics.uci.edu/ml/ on June, 2011. 